\title{
THE IMPACT OF EMERGENCY ELEARNING DURING A PANDEMIC ON UNIVERSITY FACULTY AND STUDENTS
}

\author{
Gerald E. Evans, Daniel C. Evans and Michael V. Harrington \\ College of Business, University of Montana, 32 Campus Dr. Missoula, MT 59812, USA
}

\begin{abstract}
This paper explores the impact on faculty and students of the forced transition to eLearning caused by the COVID-19 pandemic. A review of the literature on eLearning modalities and the issues involved in transitioning from face-to-face instruction is followed by a series of reports on the experiences of 11 faculty and in making the change from traditional instruction to various modalities of eLearning. The impacts on students were assessed through a survey of students in classes during the pandemic. The methodology employed is an adaptation of the grounded theory approach used in sociology along with survey research. The results indicate that the primary advantages to the transition to eLearning were the flexibility afforded both faculty and students and the ability to continue delivering quality instruction during the pandemic. The primary negatives were the difficulty in engaging students in the new delivery modalities and the significant challenges involved in proctoring exams. Prior experience with online and blended learning on the part of the faculty and students made the transition smoother.
\end{abstract}

\section{KEYWORDS}

Emergency eLearning, Online Education, Proctoring, Engagement, Flexibility

\section{INTRODUCTION}

The COVID-19 pandemic forced faculty in higher education to adapt quickly and abruptly to an eLearning environment. The question addressed here is how well faculty adapted to this forced transition and what were their positive and negative experiences. For most traditional colleges and universities, the choice was to either move instruction online or shut down. eLearning and the associated platforms became a lifeline for higher education (Müller et al. 2021) but caused much stress and anxiety among faculty. During this transition, educators had to learn how to use instructional technology, often with little training or support. They also had to become proficient in previously unused instructional modalities, as face-to-face instruction 
IADIS International Journal on WWW/Internet

was abandoned in favor of eLearning. This paper will analyze the experience of 11 university faculty with varying degrees of prior eLearning experience.

The COVID-19 pandemic was a significant disruptive event and affected every institution and the way of life for the general population. Although college-age students were at a lower mortality risk, governments and institutions forced a transition from face-to-face instruction to various modalities of eLearning using the theory of securitization (Murphy, 2020). This transition, termed "emergency eLearning" (Murphy, 2020, p 492), was sudden and caught many members of the faculty unprepared.

Müller et al. (2021) catalogued and analyzed the experiences of 14 faculty in medical disciplines at a large university in Singapore. A high level of stress and anxiety was noted along with the necessity of adjusting expectations. Key opportunities included reduced apprehension toward eLearning, greater flexibility allowing learning independence for students, reflection and examination of the teaching process, and reduction of barriers to faculty-student interaction. The challenges were more psychological than technical and included creating engagement at the social, emotional, and cognitive levels; addressing diverse student needs; and providing a holistic learning experience.

One thing that a crisis does is force change. That can be good given the innate human resistance to it (Shimoni, 2017). However, forced change is often a ragged transition. In an introduction to a special issue on blended and online learning in technical writing and communication, Slattery (2021) expressed "mixed feelings about the sudden pivot online" (p. 4). On the positive side, educators were exposed to instructional technologies they might not have otherwise tried. That is the good thing about forced change -- it forces people to try new things. On the negative side, given that most faculty had a week or less to pivot online, there was little opportunity to examine and adopt best practices in eLearning. As Slattery (2021) pointed out, it can take years for experienced faculty to develop effective online programs and progress is often in "small, incremental revisions" (p. 4). Progress in best practices in eLearning has occurred over time. Arbaugh et al. (2010) did a thorough review of online and blended learning from 1994 to 2009. They found that the field "has seen dramatic conceptual, methodological, and analytical advances" (p. 39). Within management disciplines, the progress has been uneven, with courses in organizational behavior and strategic management making the most progress, followed by human resource management, operations management, and international management. Entrepreneurship courses have seen little progress in adapting to eLearning, according to this review.

Students were also impacted by the forced transition to eLearning. Lebrague and Ballad (2021) investigated personal resilience, coping behaviors, and health considerations as predictors of lockdown fatigue. The results of their study of 243 college students found that higher levels of personal resilience and good coping skills led to less fatigue during the lockdown. Oliveira et al. (2021) examined the role of information and communications technology (ICT) platforms on the educational outcomes of teachers and students during the pandemic. Their qualitative research using structured and simi-structured interviews revealed mixed educational outcomes during the pandemic. The adoption of educational technology was generally a positive influence on educational outcomes while reluctance in personal adaptation was generally a negative influence. The physical and mental health consequences of emergency eLearning were explored by Ihm et. al. (2021). The results indicated heterogeneous impacts among students that were ameliorated by prior physical exercise regiments and strong self-efficacy. The improved overall mental and physical health benefits of physical exercise and healthy lifestyles cannot be discounted. 
The current research focuses on the experiences of students and faculty at a college of business in making the pivot to eLearning under exigent circumstances. Given a high level of diversity in their prior experience with blended and online modalities and the variety of disciplines and instructional schemes being used, each faculty member's experience was unique. As Todd et al. (2017) observed in their meta-analysis, face-to-face, online, and hybrid approaches produce different outcomes for different course content. For example, process content worked better in face-to-face delivery, whereas more structured content like compliance-based ethics instruction transitioned to eLearning more readily. For some disciplines, blended or hybrid methods produced the best instructional results. Emergency eLearning provided a social laboratory to observe and understand eLearning approaches as faculty were forced into change and to adopt unfamiliar methods and adapt well-developed approaches. This research will feature multiple cases describing the experience of faculty who had to adapt quickly to the realities of pandemic instruction. These lessons will provide the impetus for more ordered and deliberate progress in eLearning once the securitized restrictions have passed.

\section{METHODS, PROCEDURES, AND RESULTS}

\subsection{Participants}

The faculty participants for this research were 11 faculty members at an AACSB-accredited college of business in the United States who were required to transition abruptly to various eLearning modalities in response to COVID-19 safety mandates. The faculty represented several business disciplines including operations management, accounting, business law, business ethics, finance, marketing, and management. Some were broadly experienced in eLearning platforms and methodologies; others had little experience in eLearning. Some were new to higher education, filling in on short notice as COVID-19 disabled the faculty ranks because of health concerns while others were senior faculty with decades of experience in higher education. Additionally, each faculty member adapted using various eLearning modalities. Some transitioned their class to full online instruction. Others adopted a blended format of mediated synchronous instruction and asynchronous methods. A few continued face-to-face teaching with mandated rotating classroom attendance coupled with synchronous mediated instruction. Many possible permutations were represented in the case studies with a variety of outcomes.

The student participants were 166 undergraduate students at the same institution who were forced to transition to remote eLearning during the pandemic. They represented the same academic disciplines as the faculty. Most were traditional-age undergraduates, but some were nontraditional students. The students were required to adapt to whatever remote learning modality their various faculty used. 


\subsection{Methods and Procedures}

The primary intervention variable was the mandated transition from face-to-face instruction to eLearning. Faculty and students had one week to change over from face-to-face. Fortunately, the transition occurred over spring break when no instruction was scheduled so faculty could focus exclusively on the transition during that one-week period. The students, when they returned from spring break, faced the remote instructional modalities without the benefit of much input into the process. The instructional options available were rotating face-to-face with supplementary synchronous delivery, full online delivery, and blended or hybrid instruction which involved mediated synchronous delivery using Zoom or Microsoft Teams coupled with asynchronous content. Faculty were free to choose their modality for the final several weeks of the semester. The three formats continued to be used during the summer session as well as fall and spring semesters the following year. Before the pandemic, the college made extensive use of Moodle as the primary learning management system (LMS); this factor, therefore, was a constant for this investigation.

Data from faculty were collected using email-mediated reports congruent with the methods employed in grounded theory research (see Strauss and Corbin, 1994). Faculty were asked to share their experience with the transition to eLearning mandated by the security protocols. The request asked faculty to included observations on the positives and negatives they encountered as they transitioned away from face-to-face instruction. This is similar to the methodology used by Müller et al. (2021) and provided a rich set of written protocols of the faculty's experience. Faculty were classified as having high, moderate, or low experience in higher education and high, moderate, or low experience in eLearning.

Data from the students were collected through a questionnaire using 5-point Likert scales administered during the first week of the return to face-to-face instruction. The students were asked about difficulties they faced adapting to the remote eLearning technology, adapting to the remote eLearning process, and communicating with their professors. The students were also asked about how much of the content they learned compared to face-to-face instruction and their preferences for remote eLearning compared to face-to-face. Open-ended questions were asked about both positive and negative aspects of remote eLearning.

\subsection{Results}

\subsubsection{Faculty Case 1}

The first case is a senior member of the faculty with 35 years of teaching experience at the university in operations management. This participant's pre-COVID experience includes extensive use of eLearning including full televised classes, the use of several LMSs, experience in multiple synchronous mediated learning platforms including Adobe Connect, Zoom, and Microsoft Teams and fully online instruction using an LMS, narrated PowerPoint slides, and video conference technology. This participant is classified as high in higher education experience and high in eLearning experience.

The forced transition for this participant was relatively smooth and easy. This participant had video recordings of each class lecture already on hand, having planned to move the class online in the near future. All the elements in the class were installed in the LMS and the class made extensive use of Pearson MyLab where students did homework and took quizzes. The 
only transition required was regular synchronous meetings with the class using Zoom. The only difficult transition was using Zoom without an instructional technologist since all of this participant's experience with Zoom had been with the assistance of trained professionals (Campbell, 2008 and Sugar, 2005).

This participant's transition to eLearning is characterized as positive and opportunistic. The participant viewed the opportunity to manage instruction using Zoom as a personal development opportunity. The flexibility of asynchronous instruction was also viewed as an opportunity. In addition to the regular university classes, this faculty member also teaches professional pre-licensing classes in real estate that are offered for credit through the university's Center for Extended and Lifelong Learning. These classes also had to abruptly move to remote eLearning, and this provided an opportunity to expand the reach of the class and the flexibility of the teaching format.

The participant observed that the exigencies of the pandemic accelerated the trend toward online and mediated learning modalities and provided an opportunity for other faculty to venture into this arena. Most students adapted to the eLearning modality adroitly. However, students who struggled with engagement did not fare as well. The lower level of accountability in eLearning allowed students who are less disciplined to disengage, fall behind, and perform poorly. The big question is now that we have demonstrated that significant instruction can take place using various forms of eLearning, will that be the administrative mandate in a post-COVID world?

\subsubsection{Faculty Case 2}

This case is a new faculty member recruited early in the pandemic to substitute for a faculty member who was adversely affected by the pandemic. This participant had limited experience in higher education and had no experience in eLearning. This participant would be classified as low in higher education experience and low in eLearning experience. The participant teaches business ethics and social responsibility.

A prime area of concern for this participant's classes during the pandemic was the use of class time. The participant teaches three sections of Business Ethics, two of which are taught in a Hybrid format with one prerecorded lecture and one live Zoom session per week and an additional online-only section with all material presented asynchronously. In this format, all sections of the class are receiving the same prerecorded lectures on philosophical and business-oriented topics in ethics. Most of the content delivery on specific theories was reserved for the prerecorded lectures, which were done through annotated PowerPoints with voiceovers. This lecturing tool was used for the delivery of an 80-minute lecture on Nicomachean Ethics or Kantianism, lasting the entire class duration covering that specific material. For the Zoom sessions with the Hybrid classes, the live meetings of class were used to delve into thought experiments and more nuanced examinations of the theories. This combination of theory and practice may not have been possible in a pre-pandemic classroom environment given structured scheduling constraints. In order to discuss Kant's shortcomings by answering the "two rock" problem or Utilitarianism's tendency to aggregate the suffering of marginalized groups, students must first understand categorical imperatives or the greatest happiness principle. The prerecorded lectures allowed students to learn the theory at their own pace while watching the recordings, and the synchronous sessions could be used for application.

On the negative side, since there has been no in-person interaction with students, there is the problem of not knowing what a vast majority of the students look like. With over 300 students having attended classes predominantly online, the familiarity the faculty have with the students 
IADIS International Journal on WWW/Internet

is compromised. Synchronous Zoom sessions help, but it is difficult to enforce having cameras on when the classes are at 8:00 am. Student participation was low during these class times even during face-to-face instruction, so, on some mornings during the pandemic, this participant reported that it was like teaching to a computer screen.

This dynamic will change when the university returns to in-person teaching. But unfamiliarity with the students compromises the department's emphasis on undergraduate education and this faculty member's sense of belonging in the school community. As a faculty member who took on this teaching position full-time during the pandemic, it will take at least a full school year after in-person classes resume before the participant feels the same level of comfort in the department community as otherwise would have been the case.

\subsubsection{Faculty Case 3}

This instance is a senior faculty member with high experience in higher education. The participant teaches accounting primarily face-to-face, so the participant would be considered low in eLearning experience.

When face-to-face, the upper division accounting class primarily involved working through problems on the analogue white board. Unassigned problems were also worked to introduce topics, and homework problems were routinely reviewed. Both the faculty member and students were accustomed to this mode of teaching, so the transition involved an attempt to replicate this in an eLearning environment. A dedicated Zoom room with SMART boards, multiple cameras and displays, and multiple ceiling-hung microphones was used. The SMART board was described as "clunky", and the Zoom signal gave students problems, especially the gallery display being on top of the shared whiteboard. With experience, both faculty and students learned how to move the gallery display or change it to speaker view, but everyone encountered a learning curve.

Then the campus was closed, and this faculty member had to teach from home. The setup at home was better since the participant had a graphics computer with a writable screen, which worked better than the SMART board. Zoom was used and problems were worked while writing on the screen in Microsoft Word. When the actual problem was copied into Word, the process worked much better.

It took longer to write on a computer screen than an actual dry erase board in the classroom. About 15 minutes per 80-minute class was lost due to the slower medium and Zoom navigation time. The lost time required explanations to be recorded for quizzes and problems not covered in class. These were posted in Moodle.

When in the classroom, the experience reading the faces was important to the class pace and answering spontaneous questions. However, on Zoom, the "read the room" ability was completely lost. Students were asked to turn their cameras on, and that helped. Calling on students worked better but the asynchronous students fell behand as the class progressed. The University's "barrier-free" mandate in the transition required the faculty to allow asynchronous participation, but synchronous attendance would have served these students better.

Administration of quizzes required a significant adaptation. Quizzes were typically done at the start of class and time was called by watching to see when students were done or making no progress. For eLearning, McGraw-Hill's Connect was used for quizzes. Time allocation was difficult to judge and some students said they did not have enough time. The online interface took longer and added complexities compared to paper quizzes. 
Exams were also moved to McGraw-Hill Connect, but exams took much longer, even for the "A" students who were not looking up many answers. Accommodating extended time was difficult and hard to judge. Office hours were moved online via Zoom, but only a few students took the initiative to show up and participate.

\subsubsection{Faculty Case 4}

This case is an experienced management faculty member with significant experience in eLearning. The participant is classified as high in higher education experience and high in eLearning experience.

Prior to the pandemic, the participant was teaching a section online, so the face-to-face section was easily moved online using the videos and other materials that were already created. In the participant's other classes the students were focused on team projects, so only regular office hours were required.

Several guest speakers were already scheduled, and they were still able to speak via Zoom and offered great insights into what their organizations were experiencing because of COVID.

In the fall, a previously scheduled online class was taught along with two sections of an MBA organizational behavior class which switched to remote. This transition was a little difficult, but the MBA students responded well to moving discussions into Zoom. These students were quite engaged throughout.

Students were required to keep their cameras on if they had the internet bandwidth to do so. This requirement made it easier to have engaging discussions since everyone's faces were visible. The MBA students made the transition readily since most were accustomed to the hybrid program delivery in this program.

\subsubsection{Faculty Case 5}

This is a relatively new member of the faculty who teaches specialty classes in an international business center. This participant is now teaching exclusively online. The participant is classified as low in higher education experience and moderate in eLearning experience.

The participant observes that teaching classes online expands the potential student base dramatically. But it becomes even more important to plan outstanding programming that can compete with many other options for online instruction. Another factor is the increasing desire by faculty and students to avoid adding one more Zoom session to the calendar. The participant observes that it is exhausting, and that people are becoming jaded.

Online instruction makes it far easier for people to make a dramatic shift in their educational plan. Loyalties among institutions can change and online classes and can allow students to avoid moving to college. With eLearning, the power of individual personalities is muted and will not emerge sufficiently in a virtual setting to drive student loyalty and retention.

Some suggested strategies to make eLearning more impactful include bringing in professional colleagues with granular information on specific topics and business leaders who are experiencing some of the issues being discussed in class. Another strategy is to call on individual students directly to address a question at the beginning of each class and building this practice into the student expectations. A final suggested strategy is emphasizing the relevance of the material being covered to existing and future business acumen and using private sector contacts to underscore this point. 
IADIS International Journal on WWW/Internet

\subsubsection{Faculty Case 6}

A senior faculty member in management with high experience in higher education and moderate experience in eLearning is the sixth case.

On the negative side, this participant observes that the qualities of various remote teaching platforms have compromised interpersonal interaction because of the loss of nonverbal communication cues and the reduced ability of teachers and students to read interpersonal signals.

On the positive side, most students were described as "digital natives" (Prensky, 2001) and found the integration of technology into class both relevant and normal. Zoom, with its ability to chat while discussing material, allows multimodal learning in breakout rooms and enables students to create products like marketing plans or simple profit and loss statements for projects and then share their screen with the entire class for discussion.

Another positive is the ability for speakers to "join" classes through eLearning platforms from anywhere in the world; more professionals have been engaged without incurring pandemic risks and endangering students, guest lecturers, or instructors. Additionally, student projects assigned at the direction of guest instructors have resulted in content which is then immediately accessible for review and discussion. In some instances, that content has been used, with student permission, in the guest instructors' businesses.

\subsubsection{Faculty Case 7}

This case is a senior faculty member in marketing with high experience in higher education and high experience in eLearning through extensive teaching in the blended learning MBA program.

The biggest challenge reported by this participant was to get enough students to show up in the Zoom sessions and participate with good questions, answers, and comments to create a lively and engaging class. It is difficult to teach to the screen, but active and engaged students make it feel like a real classroom. Student participation can be tracked using Zoom recordings and saved chat dialogues. Students self-select active participation or chat discussion which satisfies everyone's interests and preferences.

The greatest positive is that office hours and meetings with students can be done on Zoom with individual students or the entire team for team projects. This mode is more convenient, productive, and easier to share screens and check student work. Plus, the ability to record project help sessions avoids debates on what was said and by whom. Zoom sessions can also make scheduling meetings at inconvenient hours more workable.

\subsubsection{Faculty Case 8}

This is a mid-level faculty member in business analytics with moderate experience in higher education and moderate experience in eLearning.

This participant described the most significant insight during the transition to eLearning as coming to understand how much students had been collaborating on work. The transition to online learning created many impediments to this collaborative work which had been done primarily in person before the pandemic. Students had to go through a learning curve in using various eLearning platforms for these collaborations. 


\subsubsection{Faculty Case 9}

The next case is a mid-level member of the management faculty with moderate experience in higher education and high experience in eLearning. This participant had taught several MBA classes in online and blended formats prior to the pandemic and had a baseline understanding of the technology and its capability.

The most significant negative as the semester progressed was student fatigue and drop off in engagement. By fall, the big challenge was creating an engaging Zoom experience for a class with 150 students. The participant reported feeling like equal parts group therapist and radio talk show host. On a couple of occasions, a graduate assistant was used to monitor the chat like a producer would in a radio broadcast. An adapted flipped classroom model worked best. Students were required to come to each class prepared to ask questions about topics related to the scheduled focus for the day. Current events, like the Facebook and Google anti-trust cases, provided a great foundation for illustrating various business concepts. For the spring 2021 semester, GameStop made an equally useful example.

The class format changed regularly so students could stay engaged. Some sessions were for the full group, others used small or large breakout groups. Some discussion prompts were very structured while others were open-ended. Constant experimentation and solicitation of student feedback on what worked and what did not was useful. This agile approach allowed the instructor to focus on what was important in a way that resonated with the students.

\subsubsection{Faculty Case 10}

This is a senior member of the faculty in business law who has high experience in higher education. However, this participant is low in eLearning experience since all of this participant's experience with online and blended format was with the assistance of an education technologist (Campbell, 2008 and Sugar, 2005).

A major challenge is how to limit cheating on exams. The size of the classes and the variable time needed to complete the exams can allow some students to help others. Managing test integrity is a major issue. Another challenge for this participant has been how to engage with the students. In face-to-face classes, names could be associated with faces facilitated by name tents. Solid rapport could be developed, and this personal interaction contributed to an enriched learning environment. It was felt that Zoom compromises this interaction. It is difficult to get students to leave cameras and microphones turned on. Consequently, the interactivity of the class defaults to a small subset of the students. The students who engage regularly have a much richer classroom experience.

Another challenge has been individual interactions with students. Although individual Zoom sessions are regularly offered, few students take advantage of them. Only students who wanted to review exams made the effort to meet on Zoom and they were mostly MBA students.

One opportunity is how accommodating the online modality is for students' schedules. They can review taped lectures and read the assigned materials at their convenience. During the spring 2021 registration, the two online sections filled up much earlier than the Zoom section did, suggesting that students value the convenience.

An additional opportunity is the reduced "wear and tear" on faculty, both physically and mentally. Multiple sections of the same class can be recorded once and posted on Moodle. Synchronous sessions can be scheduled once a week with recorded material filling in for the other class meetings. If students miss a class session, they can easily make it up by viewing the posted recordings. 


\subsubsection{Faculty Case 11}

The final faculty participant is a senior member of the faculty in finance who has extensive experience in eLearning prior to the pandemic. This participant is classified as having high experience in higher education and high experience in eLearning.

Prior to the forced transition, the participant had been teaching a finance class online, so the changeover was seamless. By fall, the participant was teaching both fully online sections and blended sections which incorporated some synchronous content. This participant noted no differences between the performance and engagement of the students in these two modalities. The participant used McGraw-Hill Connect with a Smart Book and this made the mediated instruction highly effective.

The primary challenge or negative aspect is that not all students have adequate equipment to fully engage in a remote environment, which requires more bandwidth than fully online. Additionally, the pace of the class is slower than the face-to-face mode, perhaps because it is more difficult to determine how students are learning the material.

On the positive side, the participant contends that quality does not have to suffer in an online environment. However, with online and remote learning, requiring assignments and other work on a specific schedule is essential to keep the students engaged.

\subsubsection{Student Questionnaire Results}

The first question in the student questionnaire asked about the difficulty in adapting to the remote learning technology. Table 1 it illustrates that over $70 \%$ of the respondents had either no difficulty or mild difficulty in adapting to the remote learning technology. Only about $30 \%$ of the respondents had moderate or significant difficulty. It appears that receiving the eLearning instructional content posed little difficulty for the students.

\section{Table 1}

How much difficulty did you have adapting to the eLearning technology?

\begin{tabular}{lc|c} 
& $\mathrm{N}$ & $\%$ \\
\hline No Difficulty & 44 & $26.5 \%$ \\
\hline Mild Difficulty & 73 & $44.0 \%$ \\
\hline Moderate Difficulty & 36 & $21.7 \%$ \\
\hline Significant Difficulty & 13 & $7.8 \%$ \\
\hline
\end{tabular}

Examining the remote eLearning process, Table 2 reveals that less than half of the student respondents had either no difficulty or mild difficulty adapting to the eLearning process. A similar number of students had either moderate or significant difficulty with the eLearning process. Only $6 \%$ had extreme difficulty. Although the students had little difficulty with the technology, the eLearning process proved difficult for most of the students. 
Table 2

How much difficulty did you have with the eLearning process?

\begin{tabular}{lr|r} 
& $\mathrm{N}$ & $\%$ \\
\hline No Difficulty & 35 & $21.1 \%$ \\
\hline Mild Difficulty & 44 & $26.5 \%$ \\
\hline Moderate Difficulty & 42 & $25.3 \%$ \\
\hline Significant Difficulty & 35 & $21.1 \%$ \\
\hline Extreme Difficulty & 10 & $6.0 \%$ \\
\hline
\end{tabular}

The difficulty students had communicating with their professor is displayed in Table 3. Examining these results, over half $(58.4 \%)$ of the student respondents had little or no difficulty communicating with their professors. Only four respondents reported extreme difficulty in communicating with their professors, leaving just under $40 \%$ who had moderate or significant difficulty.

Table 3

How much difficulty did you have communicating with your professor?

\begin{tabular}{lr|r} 
& $\mathrm{N}$ & $\%$ \\
\hline No Difficulty & 50 & $30.1 \%$ \\
\hline Mild Difficulty & 47 & $28.3 \%$ \\
\hline Moderate Difficulty & 44 & $26.5 \%$ \\
\hline Significant Difficulty & 21 & $12.7 \%$ \\
\hline Extreme Difficulty & 4 & $2.4 \%$ \\
\hline
\end{tabular}

Table 4 presents the results for how much of the course content students thought they learned in remote instruction compared to face-to-face instruction. Over $71 \%$ of the student respondents thought they learned moderately less or far less of the course content compared to face-to-face instruction. Only $18 \%$ thought they learned about the same, and $10.8 \%$ thought they learned more in the eLearning environment compared to face-to-face instruction. 
IADIS International Journal on WWW/Internet

Table 4

Compared to fact-to-face instruction, how much of the content

\begin{tabular}{lr|r}
\multicolumn{2}{c}{ did you learn? } & \\
& $\mathrm{N}$ & $\%$ \\
\hline Far Less Learning & 33 & $19.9 \%$ \\
\hline Moderately Less Learning & 85 & $51.2 \%$ \\
\hline Same Amount of Learning & 30 & $18.1 \%$ \\
\hline Moderately More Learning & 12 & $7.2 \%$ \\
\hline Far More Learning & 6 & $3.6 \%$ \\
\hline
\end{tabular}

The student preferences for the two learning modes are displayed in Table 5. Over $62 \%$ of the respondents had somewhat less or far less preference for the eLearning environment compared to the face-to-face environment. About $14 \%$ of student respondents preferred the two environments the same, and only about $23 \%$ preferred the eLearning modality more than faceto-face. Students who have experienced both eLearning and face-to-face instruction clearly preferred the face-to-face delivery modality.

Table 5

Compared to face-to-face instruction, how much did you

prefer remote eLearning?

\begin{tabular}{lr|r} 
& $\mathrm{N}$ & $\%$ \\
\hline Preferred Far Less & 50 & $30.1 \%$ \\
\hline Preferred Somewhat Less & 54 & $32.5 \%$ \\
\hline Preferred the Same & 24 & $14.5 \%$ \\
\hline Preferred Somewhat More & 23 & $13.9 \%$ \\
\hline Preferred Far More & 15 & $9.0 \%$ \\
\hline
\end{tabular}

\section{CONCLUSIONS}

Several themes emerged from the faculty reflections that were like those noted by Müller (2021). The first and most obvious point is that those who were experienced in eLearning made the transition more readily than those who lacked the experience. But, as obvious as this observation is, there is an important implication: now that all the faculty have been forced through the learning curve for eLearning, the trend in that direction will speed up. Everybody gained valuable experience in eLearning because of the forced transition. 
Student engagement in an eLearning environment is possible, but instructors must employ different techniques and methods than in face-to-face modalities. More extroverted faculty, who relied on the force of their outgoing personalities to engage students, found that method of engagement significantly compromised in an eLearning environment. More structured and deliberate mechanisms to keep students on track are needed in online and blended environments. Some examples are structured discussion questions, requiring students to keep their cameras on, calling on students, requiring students to pose questions, and assigning problem sets.

The faculty who used mediated learning platforms like McGraw-Hill Connect and Pearson MyLab, found that these tools were indispensable in moving to online and blended modes of eLearning. Learning management systems like Moodle, Blackboard, and Canvas are basic infrastructure for eLearning as are conferencing software like Zoom and Microsoft Teams. But the content-specific platforms from the major publishers augment the eLearning process in a more structured and automated manner.

Exam security was a major issue, particularly for the more technical disciplines like accounting and finance. Proctoring systems like Proctorio and Respondus are used widely in the US and Canada (see Kimmons and Veletsianos, 2021), and their adoption by universities and colleges is necessary for a more secure move to eLearning modalities like online and blended instruction.

Additionally, students need the requisite technology to fully engage in an eLearning environment. Students who lack the bandwidth and computing power to take advantage of the multimodal eLearning environment are placed in a disadvantaged position (Chuang et al, 2003). This issue could differentially impact some minority and ethnic populations whose access to technology is already limited.

Finally, the entire set of respondents noted the positive flexibility for both students and faculty that the eLearning environment afforded. There is no disagreement that online and blended education will continue to increase in higher education. Yet, many students used this new flexibility to work or pursue other endeavors that competed for their attention with university classes. The COVID-19 pandemic will undoubtably accelerate the trend toward more eLearning in higher education. Hopefully, the resources necessary to take advantage of the positive aspects of eLearning and mitigate the potential negatives will be allocated to make this transition an improvement rather than merely a change.

This accelerated move to eLearning will make the online educational environment much more crowded, and colleges and universities will have to develop specific strategies and branding to compete in the new arena. Lower on-campus student populations will present other challenges associated with bonding obligations, facilities maintenance, and participation in intercollegiate athletics.

The student questionnaire revealed patterns similar to the perceptions of the faculty. Most of the students had little difficulty adapting to the eLearning technology and in communicating with their professors. The reason why faculty may have had more difficulty with the technology is that originating an eLearning lecture is more complex than receiving. Almost $80 \%$ of the student respondents had some level of difficulty with the learning process in an eLearning environment (see Table 2). Additionally, over $71 \%$ thought they learned less in the eLearning environment (see Table 4). Not surprisingly, over $62 \%$ preferred the eLearning environment less than the face-to-face environment. Significantly, and not unexpectedly, only about $23 \%$ preferred eLearning over face-to-face (see Table 5). Perhaps the fact that students have experienced over a year of eLearning with less than a quarter of them preferring this educational modality will slow the migration from face-to-face instruction to eLearning. 
IADIS International Journal on WWW/Internet

The open-ended questions provide some insight into the quantitative results. The major negatives reported by students included social isolation and the resulting mental health struggles associated with eLearning. These comments are congruent with those reported by Ihm et. al. (2021). Students also reported difficulties staying engaged in the educational process, staying motivated, and focusing their attention. Many students reported that their grades suffered and they learned less. The distractions that came with learning from home and managing the technology were also negatives reported by many students. Flexibility in various forms was the most often cited positive of the transition to the eLearning environment. Students reported that they could work at their own pace, manage their schedule better, and continue or start working at a job when classes were delivered in an eLearning modality. Some also reported saving money on gasoline since they did not have to commute to campus.

These research findings are important and significant. The most instructive takeaway for faculty is that they were able to adapt and deliver a high-quality educational experience. Prior to the forced transition, many faculty voiced misgivings concerning the quality of courses delivered online. The data presented here support the conclusion that online does not necessarily mean lower quality. Online instruction can produce educational outcomes of equal quality as face-to-face instruction (see Clouse and Evans, 2003). A second conclusion is that for many of the difficulties encountered during the transition, faculty were able to adapt, find or invent new methods, and generally make it work. Thus, the educational process is robust and can withstand external shocks. Perhaps the most significant and long-lasting conclusion from this research is that virtually all university faculty have now acquired the skillset necessary for online instruction. The silver lining in the COVID-19 pandemic for higher education is that, in a very short period, all the faculty members who participated in our research acquired the skills necessary to teach effective online courses. This legacy will inevitably expand the quality and scope of eLearning.

The forced transition to eLearning was more stressful for students. With traditional online learning, students elect to take an online class and thus choose this educational modality over face-to-face instruction. When everyone is compelled to learn in an eLearning environment, the element of choice is removed and the resulting frustration, stress, and mental health issues become apparent. Perhaps the most significant takeaway from forced eLearning during a pandemic is that providing an eLearning option for most class offerings is both feasible and desirable, but requiring eLearning as the only modality is unwise.

\section{REFERENCES}

Arbaugh, J. B. et al, 2010. A Review of Research on Online and Blended Learning in the Management Disciplines: 1994-2009. Organization Management Journal, Vol. 7, No. 1, 39-55.

Campbell, T., 2008. The Capacity of Instructional Technologists to Provide Systemic Support for Science Education Reform. Teacher Development, Vol. 12, No. 1, 67-83.

Chuang, H. H. et al, 2003. Faculty Technology Mentoring Programs: Major Trends in the Literature. Journal of Computing in Teacher education, Vol. 19, No. 4, 101-106.

Clouse, S. F., \& Evans, G. E., 2003. Graduate Business Students' Performance with Synchronous and Asynchronous Interaction e-Learning Methods. Decision Sciences Journal of Innovative Education, Vol. 1, No. 2, 181-202. 


\section{THE IMPACT OF EMERGENCY ELEARNING DURING A PANDEMIC ON UNIVERSITY}

FACULTY AND STUDENTS

Ihm, L., Zhang, J. et al, 2021. Impacts of the COVID-19 Pandemic on the Health of University Students. The International Journal of Health Planning and Management, Vol. 36, No. 3, 618-627. https://doi.org/10.1002/hpm.3145

Kimmons, R and Veletsianos, G., 2021. Proctoring Software in Higher Ed: Prevalence and Patterns. Educause Cybersecurity \& Privacy. https://er.educause.edu/articles/2021/2/proctoring-software-inhigher-ed-prevalence-and-patterns.

Lebrague, L. J. and Ballad, C. A., 2021. Lockdown Fatigue Among College Students During the COVID-19 Pandemic: Predictive Role of Personal Resilience, Coping Behaviors, and Health. Perspectives in Psychiatric Care, 2021, 1-8. https://doi.org/10.1101/2020.10.18.20213942

Müller, A. M. et al, 2021. COVID-19 Emergency eLearning and Beyond: Experiences and Perspectives of University Educators. Education Sciences, Vol. 11, No. 1, 19 https://doi.org/10.3390/educsci11010019

Murphy, M. P., 2020. COVID-19 and Emergency eLearning: Consequences of the Securitization of Higher Education for Post-Pandemic Pedagogy. Contemporary Security Policy, Vol. 41, No. 3, 492-505.

Oliveira, G. et al, 2021. An Exploratory Study on the Emergency Remote Education Experience of Higher Education Students and Teachers During the COVID-19 Pandemic. British Journal of Educational Technology, Vol. 52, No. 4, 1357-1376. https://doi.org/10.1111/bjet.13112

Prensky, M., 2001. Digital Natives, Digital Immigrants part 2: Do They Really Think Differently? On the Horizon, Vol. 9, No. 6, 1-6. https://doi.org/10.1108/10748120110424843

Shimoni, B., 2017. What is Resistance to Change? A Habitus-Oriented Approach. Academy of Management Perspectives, Vol. 31, No. 4, 257-270.

Slattery, D. M., 2021. Guest Editor's Introduction: Facilitating Interaction, Collaboration, Community, and Problem-Solving Capabilities in Blended and Fully Online Technical Communication Programs: An Introduction to the Special Issue. Journal of Technical Writing and Communication, Vol. 51, No. 1, 3-10.

Strauss, A. \& Corbin, J., 1994. Grounded Theory Methodology. In N. K. Denzin \& Y. S. Lincoln (Eds.) Handbook of Qualitative Research (pp. 217-285). Thousand Oaks: Sage Publications.

Sugar, W., 2005. Instructional Technologist as a Coach: Impact of a Situated Professional Development Program on Teachers' Technology Use. Journal of Technology and Teacher Education, Vol. 13, No. 4, 547-571.

Todd, E. M. et al, 2017. A Meta-Analytic Comparison of Face-to-Face and Online Delivery in Ethics Instruction: The Case for a Hybrid Approach. Science and Engineering Ethics, Vol. 23, No. 6, $1719-1754$ 